\title{
Assessment of a mitral valve replacement skills trainer: A simplified, low-cost approach
}

David G. Greenhouse, MD, Eugene A. Grossi, MD, Sophia Dellis, BA, Joy Park, BS, David W. Yaffee, MD, Abe DeAnda, Jr, MD, Aubrey C. Galloway, MD, and Leora B. Balsam, MD

Objectives: Simulated mitral valve replacement may aid in the assessment of technical skills required for adequate performance in the operating room. We sought to design and assess a mitral valve replacement training station that is low-cost, nonperishable, portable, and reproducible as a first step in developing a mitral valve surgical skills curriculum.

Methods: Nineteen physicians ( 7 general surgery residents, 8 cardiothoracic surgery residents, and 4 attending cardiothoracic surgeons) underwent simulated mitral valve replacement testing. Simulated mitral valve replacement was performed on a training station consisting of a replaceable "mitral annulus" inside a restrictive "left atrium." Eight components of performance were graded on a 5-point scale. A composite score (100 point maximum) was calculated by weighting the grades by procedural time. The effect of training level was evaluated using analysis of variance and post hoc Tukey honestly significant difference.

Results: The speed of simulated mitral valve replacement varied among general surgery residents, cardiothoracic surgery residents, and attending cardiothoracic surgeons ( $52.9 \pm 9.0$ vs $32.8 \pm 4.7$ vs $28.0 \pm 3.5$ minutes, respectively; $\mathrm{F}=25.3 ; P<.001)$. Level of training significantly affected all 8 evaluation components $(P<.001)$. Composite scores increased with level of training (general surgery residents $32.9 \pm 11.4$, cardiothoracic surgery residents $65.1 \pm 11.5$, and attending cardiothoracic surgeons $88.3 \pm 7.8$ of a possible 100 points; $\mathrm{F}=35.7$; $P<.001)$. Cardiothoracic surgery residents who reported having performed 10 to 50 mitral valve replacements as the primary surgeon had a composite score of $65.0 \pm 2.8(P<.01$ compared with attending cardiothoracic surgeons).

Conclusions: Simulated mitral valve replacement can be performed using this simple, affordable, portable setup. Performance scores correlate with level of training and experience, but residents who performed 10 to 50 mitral valve replacements still failed to reach attending-level proficiency. This training simulator may facilitate skills practice and evaluation of competency in cardiac surgery trainees. (J Thorac Cardiovasc Surg 2013;145:54-59)

丹 Supplemental material is available online.

Cardiac surgery trainees are faced with specific challenges when learning to perform mitral valve surgery. Proper exposure of the valve must be established, with approaches ranging from conventional sternotomy to minimally invasive minithoracotomy. The geometric constraints of the surgical field, combined with the close proximity of the mitral valve

\footnotetext{
From the Department of Cardiothoracic Surgery, New York University School of Medicine, New York, NY.

Funding for this research was provided by a grant from the Thoracic Surgery Foundation for Research and Education (to Dr Balsam).

Disclosures: Authors have nothing to disclose with regard to commercial support.

Read at the 92nd Annual Meeting of The American Association for Thoracic Surgery, San Francisco, California, April 28-May 2, 2012.

Received for publication April 24, 2012; revisions received Aug 20, 2012; accepted for publication Sept 27, 2012; available ahead of print Oct 29, 2012.

Address for reprints: Leora B. Balsam, MD, NYU Medical Center, 530 First Ave, Suite 9V, New York, NY 10016 (E-mail: leora.balsam@nyumc.org). 0022-5223/\$36.00

Copyright (c) 2013 by The American Association for Thoracic Surgery http://dx.doi.org/10.1016/j.jtcvs.2012.09.074
}

to other critical cardiac structures, can make precise suture placement difficult or hazardous for the novice surgeon. Although procedural volume and experience have been shown to affect the choice of surgical technique and outcomes, mandatory duty-hour restrictions have led to decreased cardiac case volumes for cardiothoracic surgery residents. ${ }^{1-3}$ Surgical simulators allow for technical skill development in a safe, controlled environment, which may translate into improved performance in the operating room. ${ }^{4-6}$

Previous mitral valve surgery simulators have used expensive proprietary models or perishable animal tissue. ${ }^{7}$ We sought to design an inexpensive, reusable mitral valve replacement (MVR) skills training station (TS) using commonly found materials. We designed our TS to be easily portable with an adjustable yet reproducible setup configuration. This TS platform provides not only a tool to study the performance of residents and fellows at simulated MVR (sMVR) but also a practice station that can be easily distributed and used for home practice.

We aimed to assess the TS by relating the performance on sMVR to the level of surgical training. This study is a first step in the evaluation of this platform for teaching the basic 


\section{Abbreviations and Acronyms \\ ICC = intraclass correlation coefficient \\ MVR $=$ mitral valve replacement \\ SMVR $=$ simulated mitral valve replacement \\ TS $=$ training station}

steps of MVR, with a focus on correct suture placement in a geometrically constrained space. Studying the technical differences in sMVR performance between inexperienced and experienced subjects may lead to better understanding of the surgical learning process and identification of areas to focus training.

\section{MATERIALS AND METHODS Subjects}

Nineteen surgeons from a single institution underwent sMVR evaluation: 7 general surgery residents, 8 cardiothoracic surgery residents, and 4 attending cardiothoracic surgeons. General surgery residents were in postgraduate year $2(n=3)$ or $3(n=4)$. Cardiac surgery residents were in postgraduate year $4(n=1), 6(n=4), 9(n=2)$, or $10(n=1)$. Two cardiac surgery residents were enrolled in an integrated 7-year cardiac surgery/general surgery training program, whereas 6 cardiac surgery residents were enrolled in a traditional fellowship program after completion of general surgery training. Two cardiac surgery residents had performed 10 to 50 MVRs as primary surgeon, whereas the remaining 6 had performed less than 10. Institutional review board approval was obtained for the conduct of this study.

\section{Trainer Construction}

The mitral valve trainer was constructed by hand from materials commonly found at a hardware store. A 3- to 4-inch polyvinyl chloride pipe adapter was lined with felt in 2 layers using hot glue. An additional 2-ply ring of felt was glued en face inside the adapter, creating an annulus-like structure. This polyvinyl chloride structure was then glued to a suction-based mounting arm (The Chamberlain Group, Great Barrington, Mass). To reproduce the geometric restrictions of the left atrium when working through a sternotomy, the assembly was placed within a rigid chest wall model (Heart Case, The Chamberlain Group) (Figure 1). By using ruler-tapes, a 3-dimensional coordinate system was constructed within the Heart Case to ensure reproducible "annular" positioning between tests (Figure E1). A suture organizer was placed around the opening of the Heart Case. The approximate cost of the trainer was $\$ 40$ (excluding the Heart Case), and it took approximately 15 minutes to construct each assembly.

\section{Protocol}

Before testing, all subjects watched an 8-minute demonstration video that illustrated the steps of sMVR on the task trainer and highlighted important technical details, including suture spacing, suture depth, and suture organization. The video is broken down into several segments: annular suture placement, suture organization, sewing ring suture placement, and knot tying. A narration accompanies the video. After viewing the video, subjects were instructed to wear their surgical loupes as usual and a headlampmounted video camera. The video camera tracked the operative field of view of the subject's loupes, and video was recorded to a DVD. The subject was given standard surgical instruments (forceps, low-profile long needle driver, scissors) along with double-armed pledgeted 2-0 Ethibond suture (Ethicon, Somerville, NJ) material to complete the MVR using the sewing ring of an expired prosthetic valve. The subjects were provided an assistant who would hold the suture or sewing ring as directed by the subject. Times to completion of annular suture placement, sewing ring suture placement, and tying of the final knots were recorded. At the conclusion of the test, all samples were collected for grading (Figure E2). Subjects were unaware of the grading methods. All videos and sMVR samples were deidentified before assessment.

\section{Grading and Assessment}

Two blinded reviewers with surgical expertise assessed all video and sMVR samples in an independent fashion. An evaluation sheet was used to grade performance on a 1 to 5 scale $(1=$ poor, unable to accomplish goal, marked hesitation; 2 = below average, able to partially accomplish goal with hesitation; 3 = average, able to accomplish goal with hesitation, discontinuous progress and flow; 4 = good, able to accomplish goal deliberately, with minimal hesitation, showing good progress and flow; $5=$ excellent, able to accomplish goal without hesitation, showing excellent progress and flow) in the following categories: suture bite size, suture spacing, needle driver facility, needle angle awareness, needle followthrough, awareness of geometric constraints, accuracy, and knot tying (Table 1). A composite score was calculated by adding the scores in each of the 8 subjective categories from both graders ( 80 points maximum) to a time to completion subscore $(<30$ minutes $=20$ points; $30-35$ minutes $=15$ points; $35-40$ minutes $=10$ points $; 40-45$ minutes $=5$ points; $>45$ minutes $=0$ points) for a maximum score of 100 points.

In addition, graders recorded whether or not errors were made in each of 4 quadrants of the annulus during suture placement (anterolateral, anteromedial, posterolateral, and posteromedial quadrants). Tabulated errors included multiple needle reloads to achieve the necessary suture bite, incorrect suture bite size or depth, and malpositioning of pledgets. Observations were compared between graders, and if both graders reported errors within a quadrant, this was analyzed as an error. If there was no agreement between graders within a quadrant, it was analyzed as no error. Specific comments were recorded such that detailed feedback could be provided to the subjects at a later date.

\section{Exit Survey}

After the completion of sMVR, subjects were asked to complete a 14-item exit-survey regarding their experience. Items were rated by their agreement with or estimated value of the statement on a 1 to 5 Likert scale ( $1=$ strongly disagree, $3=$ neutral, $5=$ strongly agree $)$.

\section{Statistical Methods}

Scores were compared among levels of training using analysis of variance. Pairwise comparisons were analyzed using post hoc Tukey honestly significant difference. The presence of errors was compared between quadrants using a nonparametric Cochran's Q test. Intergrader variability was analyzed using intraclass correlation coefficient (ICC).

\section{RESULTS}

The time required to complete sMVR varied among general surgery residents, cardiothoracic surgery residents, and attending cardiothoracic surgeons: $52.9 \pm 9.0$ versus $32.8 \pm 4.7$ versus $28.0 \pm 3.5$ minutes, respectively; $\mathrm{F}=25.3, P<.001$. Pairwise comparison demonstrated no significant difference between cardiothoracic surgery residents and attending cardiothoracic surgeons in time to complete sMVR, whereas general surgery residents versus cardiothoracic surgery residents and general surgery residents versus attending cardiothoracic surgeons were significantly different $(P<.05)$ (Table 2$)$. 

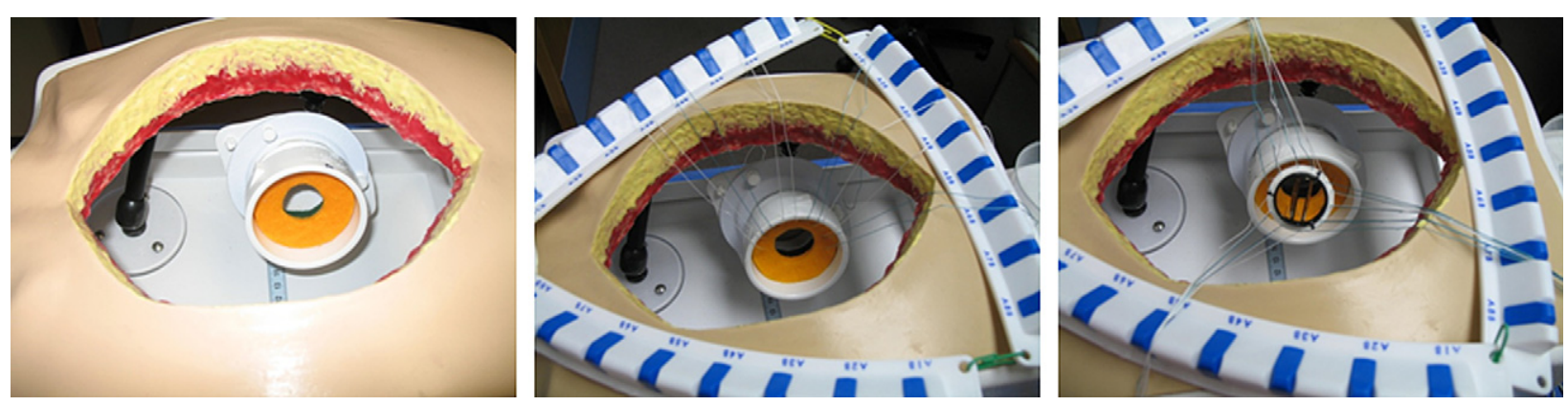

FIGURE 1. Setup of simulated mitral valve replacement training station. A replaceable "mitral insert" is mounted on an adjustable arm within the chest cavity model according to a 3-dimensional coordinate system.

The level of training significantly affected all 8 evaluation components $(P<.001)$ (Table 2$)$. In addition, all pairwise comparisons among levels of training were significantly different $(P<.05)$ for needle angle awareness, awareness of geometric constraints, knot tying, and needle driver facility. There was no significant difference between cardiothoracic surgery residents and attending cardiothoracic surgeons for suture bite size, suture spacing, and accuracy.

Composite scores varied with experience (general surgery residents $32.9 \pm 11.4$, cardiothoracic surgery residents $65.1 \pm 11.5$, attending cardiothoracic surgeons $88.3 \pm 7.8$; $\mathrm{F}=35.7 ; P<.001)$ and were significantly different between all paired comparisons $(P<.05)$ (Figure 2$)$. Cardiothoracic surgery residents who reported having performed 10 to 50 MVRs as primary surgeon had a composite score of 65.0 \pm 2.8 ( $P<.01$ compared with attending cardiothoracic surgeons). Interobserver grade correlation was strong $(\mathrm{ICC}=0.67, P<.01)$.

Graders made several observations during sMVR. Of note, the region corresponding to the anterior annulus presented a greater challenge to the subjects in terms of suture placement, needle angles, and pledget positioning. The anteromedial quadrant had the greatest frequency of observed errors committed by subjects (Table 3 ). There was a significant difference in error rate by level of training in the anterolateral quadrant $(P=.001)$. For all subjects together, the error rate varied significantly by quadrant $(P=.01)$, with the least error in the posterolateral quadrant and the greatest error in the anteromedial quadrant. In addition, several major errors committed by trainees were observed: poorly planned suture placement in the sewing ring requiring removal and replacement of stitches; strut entrapment by a suture; incorrect valve orientation; passing one stitch through another, which then prevented successful parachuting of the valve; and crossing stitches before putting them through the sewing ring.

Exit survey results are shown in Table 4. There was no statistically significant effect by level of training on survey results (analysis of variance). The strongest agreement was with the statements: "This simulator is easy to use" ( $4.7 \pm$ 0.6 ), "I would use this simulator to prepare for an MVR" $(4.6 \pm 0.6)$, and "This simulator is a useful adjunct in preparing a resident for an MVR" $(4.6 \pm 0.6)$. The strongest disagreement was with the statement: "The simulator is a good substitute for the operating room" $(2.6 \pm 1.5)$.

\section{DISCUSSION}

We successfully designed and constructed an sMVR TS that was inexpensive, portable, reusable, and nonperishable. The study results demonstrate that SMVR performance differed by level of training using both subjective and

TABLE 1. Performance assessment based on 5-point scale

\begin{tabular}{|c|c|c|c|c|c|}
\hline & Poor & $\begin{array}{c}\text { Below } \\
\text { average }\end{array}$ & Average & Good & Excellent \\
\hline Suture bite (no skiving, proper entry/exit points, appropriate distance around annulus) & 1 & 2 & 3 & 4 & 5 \\
\hline Suture spacing (symmetry of stitches, placed systematically, correct number of punctures/advances) & 1 & 2 & 3 & 4 & 5 \\
\hline Use of needle driver (needle not loaded more than halfway back, enters at 90 degrees, facility) & 1 & 2 & 3 & 4 & 5 \\
\hline $\begin{array}{l}\text { Needle angles (minimal needle reload because of improper angle, correct angle relative to tissue, } \\
\text { and needle driver) }\end{array}$ & 1 & 2 & 3 & 4 & 5 \\
\hline Needle follow-through (exits tissue with appropriate follow-through) & 1 & 2 & 3 & 4 & 5 \\
\hline Awareness of geometric constraints (works well in cavity, "overhand" approach on posterior annulus) & 1 & 2 & 3 & 4 & 5 \\
\hline Accuracy of stitches (pledgets aligned, spacing on ring, accurate use of bicolor suture) & 1 & 2 & 3 & 4 & 5 \\
\hline Knot tying (correct pairing of sutures, adequate tension, facility, finger and hand follow-through) & 1 & 2 & 3 & 4 & 5 \\
\hline
\end{tabular}

Modified with permission from Fann JI, Caffarelli AD, Georgette G, Howard SK, Gaba DM, Youngblood P, et al. Improvement in coronary anastomosis with cardiac surgery simulation. J Thorac Cardiovasc Surg. 2008;136:1486-91. 
TABLE 2. Simulated mitral valve replacement performance scores by level of training

\begin{tabular}{|c|c|c|c|c|}
\hline & $\begin{array}{l}\text { General surgery } \\
\text { residents }(n=7)\end{array}$ & $\begin{array}{l}\text { Cardiac surgery } \\
\text { residents }(n=8)\end{array}$ & $\begin{array}{l}\text { Attending cardiac } \\
\text { surgeons }(n=4)\end{array}$ & ANOVA \\
\hline Time to completion*,$\dagger(\mathrm{min})$ & $52.9 \pm 9.0$ & $32.8 \pm 4.7$ & $28.0 \pm 3.5$ & $\begin{array}{l}\mathrm{F}=25.3 \\
P<.001\end{array}$ \\
\hline Suture bite size*,$\dagger(1-5$ scale $)$ & $1.8 \pm 0.6$ & $2.9 \pm 0.8$ & $3.8 \pm 0.9$ & $\begin{array}{l}\mathrm{F}=11.9 \\
P=.001\end{array}$ \\
\hline Suture spacing $* \nmid \dagger(1-5$ scale $)$ & $1.6 \pm 0.6$ & $3.0 \pm 0.7$ & $3.8 \pm 0.6$ & $\begin{array}{l}\mathrm{F}=15.6 \\
P<.001\end{array}$ \\
\hline Needle driver facility* $, \dagger, \ddagger$ (1-5 scale) & $2.1 \pm 0.6$ & $3.1 \pm 0.7$ & $4.6 \pm 0.3$ & $\begin{array}{l}\mathrm{F}=21.8 \\
P<.001\end{array}$ \\
\hline Needle angle use $*, \dagger, \ddagger$ (1-5 scale) & $1.6 \pm 0.7$ & $2.9 \pm 0.6$ & $4.3 \pm 0.6$ & $\begin{array}{l}\mathrm{F}=21.1 \\
P<.001\end{array}$ \\
\hline Needle follow-through $\dagger, \ddagger(1-5$ scale $)$ & $2.9 \pm 0.5$ & $3.3 \pm 0.6$ & $4.8 \pm 0.3$ & $\begin{array}{l}\mathrm{F}=18.4 \\
P<.001\end{array}$ \\
\hline Awareness of geometric constraints $*, \dagger, \ddagger(1-5$ scale $)$ & $1.5 \pm 0.5$ & $2.9 \pm 0.7$ & $4.8 \pm 0.3$ & $\begin{array}{l}\mathrm{F}=38.5 \\
P<.001\end{array}$ \\
\hline Accuracy* ${ }^{*} \dagger(1-5$ scale $)$ & $1.6 \pm 0.6$ & $2.9 \pm 0.7$ & $4.0 \pm 0.9$ & $\begin{array}{l}\mathrm{F}=16.2 \\
P<.001\end{array}$ \\
\hline Knot tying* $* \dagger, \ddagger(1-5$ scale $)$ & $2.6 \pm 0.7$ & $3.8 \pm 0.5$ & $4.9 \pm 0.3$ & $\begin{array}{l}\mathrm{F}=23.0 \\
P<.001\end{array}$ \\
\hline Composite score without time adjustment*,,$\dagger$, (1-80 scale) & $31.4 \pm 8.6$ & $49.5 \pm 7.8$ & $69.5 \pm 6.6$ & $\begin{array}{l}\mathrm{F}=30.0 \\
P<.001\end{array}$ \\
\hline Composite score* $, \dagger, \ddagger(1-100$ scale $)$ & $32.9 \pm 11.4$ & $65.1 \pm 11.5$ & $88.3 \pm 7.8$ & $\begin{array}{l}\mathrm{F}=35.7 \\
P<.001\end{array}$ \\
\hline
\end{tabular}

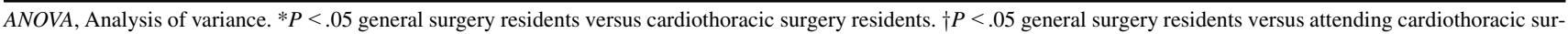

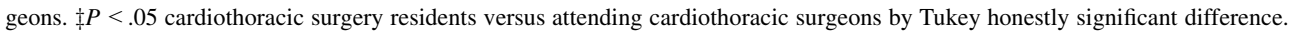

objective measures. Significant gaps in performance between cardiac surgery residents and attending cardiac surgeons in sMVR were observed. Although cardiac surgery residents and attendings performed sMVR within a similar amount of time, attending surgeons performed a more "masterful" sMVR, outperforming residents in 4 of 8

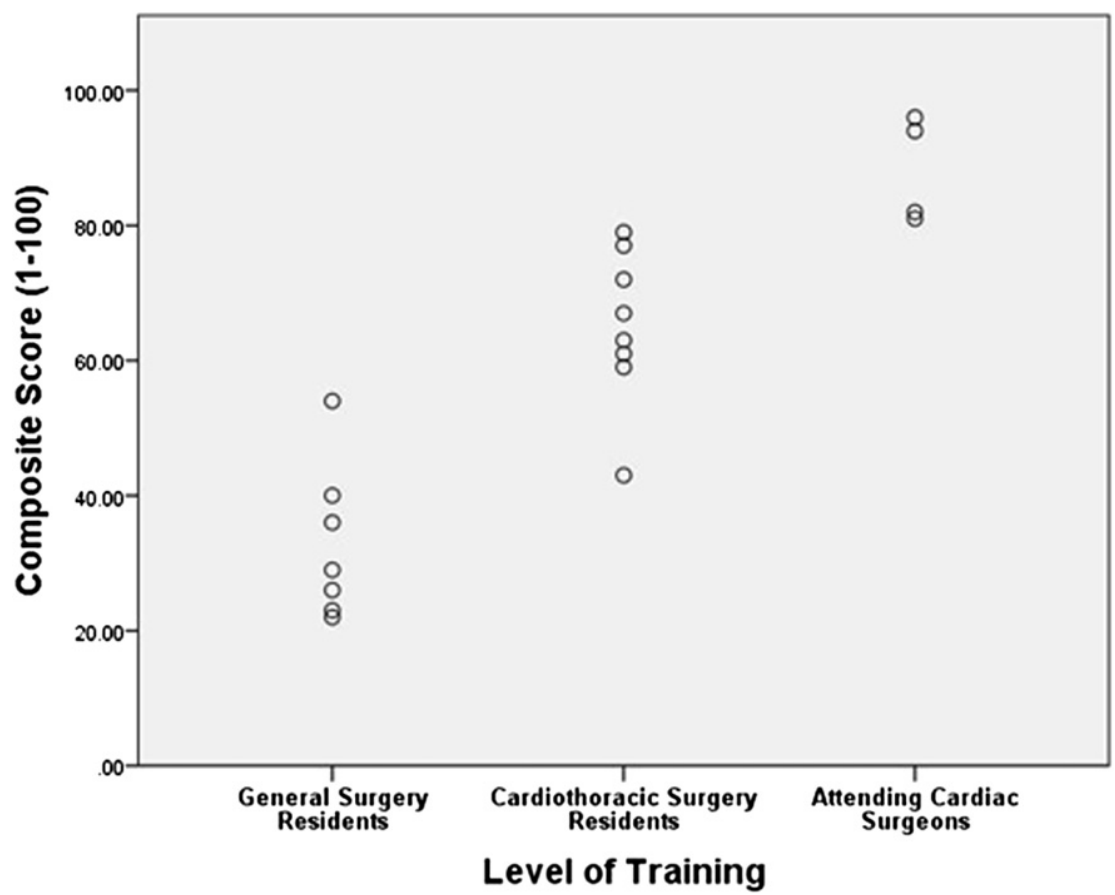

FIGURE 2. Composite scores on simulated mitral valve replacement exercise differed significantly among all levels of training $(P<.05)$. 
TABLE 3. Percent of subjects committing technical errors within four quadrants of the annulus

\begin{tabular}{|c|c|c|c|c|c|}
\hline Quadrant & Total $(n=19)$ & $\begin{array}{l}\text { General surgery residents } \\
\qquad(\mathrm{n}=7)\end{array}$ & $\begin{array}{l}\text { Cardiac surgery residents } \\
\qquad(\mathbf{n}=8)\end{array}$ & $\begin{array}{l}\text { Attending cardiac surgeons } \\
\qquad(\mathbf{n}=4)\end{array}$ & ANOVA \\
\hline Anterolateral & $57.9 \%$ & $100.0 \%$ & $50.0 \%$ & $0.0 \%$ & $\begin{array}{l}\mathrm{F}=10.5 \\
P=.001\end{array}$ \\
\hline Anteromedial & $68.4 \%$ & $85.7 \%$ & $62.5 \%$ & $50.0 \%$ & $\begin{array}{l}\mathrm{F}=0.8 \\
P=.47\end{array}$ \\
\hline Posterolateral & $26.3 \%$ & $57.1 \%$ & $12.5 \%$ & $0.0 \%$ & $\begin{array}{l}\mathrm{F}=3.4 \\
P=.06\end{array}$ \\
\hline Posteromedial & $36.8 \%$ & $57.1 \%$ & $37.5 \%$ & $0.0 \%$ & $\begin{array}{l}\mathrm{F}=1.9 \\
P=.19\end{array}$ \\
\hline
\end{tabular}

Significant effect of quadrant on total error rate by Cochran's Q test, $P=.01$. ANOVA, Analysis of variance.

subjective categories. Even those cardiac surgery residents who had performed 10 to 50 MVRs as primary surgeon scored significantly worse than attendings at sMVR. Whether these differences in performance of sMVR correlate to live operating room performance remains to be determined.

Surgical skills training faces increasing challenges. Work-hours restrictions, increasing numbers of novice surgeons entering integrated training programs, and increasing case complexity and variation all contribute to the need for skills training outside of the operating room. Research into the development of expertise suggests that high degrees of repetition $(>10,000$ hours $)$ are required to develop mastery. ${ }^{8}$ It seems increasingly unlikely that the number of repetitions required to gain proficiency in cardiac procedures will be met in the operating room during a cardiac residency; task trainers may prove useful in achieving that goal. ${ }^{4-7}$

TABLE 4. Exit survey results

\begin{tabular}{lc}
\hline & $\begin{array}{c}\text { Response } \\
\text { Mean } \pm \text { SD }(\mathbf{n}=\mathbf{1 7})\end{array}$ \\
\hline $\begin{array}{l}\text { Surgical simulation is a necessary component in } \\
\text { the future of training cardiothoracic residents. }\end{array}$ & $4.3 \pm 1.0$ \\
This simulator is easy to use. & $4.7 \pm 0.6$ \\
This simulator teaches key points necessary for & $4.5 \pm 0.6$ \\
$\quad$ performing an MVR. & $4.6 \pm 0.6$ \\
This simulator is a useful adjunct in preparing a & \\
$\quad$ resident for MVR. & $4.2 \pm 1.0$ \\
This simulator covers key learning points about & \\
$\quad$ the technique of MVR. & $2.6 \pm 1.5$ \\
The simulator is a good substitute for the OR. & $4.5 \pm 0.6$ \\
Simulation training improves my technical skills. & $4.6 \pm 0.6$ \\
I would use this simulator to prepare for MVR. & $3.8 \pm 1.1$ \\
I would use the simulator if the work week & $4.3 \pm 1.1$ \\
$\quad$ was $<80$ h. & $3.8 \pm 1.0$ \\
I enjoyed this simulator. & $4.0 \pm 0.9$ \\
Value of written quiz & $4.1 \pm 0.8$ \\
Value of instructional video & $4.1 \pm 1.0$ \\
Value of timed performance & \\
Value of recorded MVR simulation & \\
Agreement with statement measured on 1 to 5 scale: $1=$ strongly disagree, \\
3 = neutral, $5=$ strongly agree. There was no significant effect by level of training \\
on survey answers for any question (analysis of variance). SD, Standard deviation; \\
$M V R$, mitral valve replacement; OR, operating room.
\end{tabular}

Exit survey results from this study suggest agreement between attendings and trainees that SMVR could be a valuable adjunct to skills training. Although all parties agreed that sMVR does not replace the experience gained from the operating room, their responses do suggest that it may be a useful learning tool for preparation and skill development.

This study examined the role of sMVR in skills assessment and was not designed to evaluate its role in skills training; however, several important technical observations were made during this study. First, we witnessed several major errors made by trainees during sMVR, including poorly planned suture placement in sewing ring requiring removal and replacement of stitches, strut entrapment by a suture, incorrect valve orientation, passing one stitch through another, and crossing stitches before putting them through the sewing ring. sMVR provides a safe environment where technical errors can be made and learned from. In addition, we observed that errors were made along the anterior annulus more frequently than along the posterior annulus. We suspect that this is due to challenging needle angles caused by geometric constraints. Recording and analyzing the "geography" of technical errors may greatly aid in focused, targeted practice, coaching, and feedback. Simulation may move some of the "trial and error" learning process from the operating room to the "simulation laboratory."

This study focused on the technical skills of suture placement in a restricted cavity requiring realistic and challenging needle angles. The purpose of this task trainer was to assess awareness of geometric constraints, needle angle, body positioning, and needle driver facility in challenging anatomic configurations associated with MVR. These basic skills are requisite building blocks for any mitral valve procedure. The TS also can be adapted to ring annuloplasty implantation without significant modification, and we plan to evaluate this task in the future.

\section{Study Limitations}

This study aimed only to assess the ability of an SMVR TS to evaluate and differentiate performance by level of training. Future study will be required to determine the 
longitudinal effect of practice with the skills station on performance. Despite the subjective evidence that sMVR has education utility as assessed by exit survey results and our own anecdotal experience, objective validation that practice with an SMVR TS generates improved operating room performance will require significant additional study. This may be approached in 1 of 2 ways: evaluation of operating room performance before and after focused training with sMVR or demonstration that practice with sMVR leads to improved SMVR scores with concomitant correlation of sMVR scores with operating room performance. These studies are ongoing at the New York University School of Medicine.

An additional limitation is that this research was conducted at a single institution with a limited number of participants. Only 2 graders evaluated the subjects, and despite a high ICC, further study of intergrader reliability is warranted. An expanded, multi-institutional study may help validate our results.

We elected to design a low-fidelity skills station as a key component of a mitral valve surgery skills curriculum. Material characteristics of our TS were not identical to natural tissue, and in certain respects the trainer was not anatomically faithful. We purposefully used synthetic materials to allow for home practice with a nonperishable setup. Furthermore, our trainer consisted of an annulus without valve leaflets. At the New York University School of Medicine, we teach regional mitral valve anatomy using separate tools. There is evidence that low-fidelity skills trainers are not inferior to high-fidelity setups for teaching technical skills. ${ }^{9,10}$ By using a low-fidelity model, we reduced the number of variables, allowing the trainee and trainer to focus on perfecting and teaching a specific small set of tasks. We believe that a complex, high-fidelity trainer, allowing for variations in anatomy and unexpected surgical circumstances, is another key component of a complete surgical curriculum that remains to be developed. Future iterations of our TS may attempt to more accurately reproduce the anatomy and tissue-handling properties of the native human mitral valve. We also hope to allow for quantitative measures of quality (eg, testing for paravalvular leaks).

\section{CONCLUSIONS}

This study presents an sMVR skills station that is simple, inexpensive, portable, and reproducible. We suggest that such a trainer may form the backbone of a mitral valve surgery skills curriculum that would include deliberate distributed practice, repeated assessments, and directed feedback. Future studies are needed to demonstrate the effect of unsupervised practice on resident performance in the operating room.

\section{References}

1. Northrup WF, Kshettry VR, DuBois KA. Trends in mitral valve surgery in a large multi-surgeon, multi-hospital practice, 1979-1999. J Heart Valve Dis. 2003;12: 14-24.

2. Hannan EL, Odonnell JF, Kilburn H, Bernard HR, Yazici A. Investigation of the relationship between volume and mortality for surgical-procedures performed in New York State hospitals. JAMA. 1989;262:503-10.

3. Connors RC, Doty JR, Bull DA, May HT, Fullerton DA, Robbins RC. Effect of work-hour restriction on operative experience in cardiothoracic surgical residency training. J Thorac Cardiovasc Surg. 2009;137:710-3.

4. Fann JI, Caffarelli AD, Georgette G, Howard SK, Gaba DM, Youngblood P, et al. Improvement in coronary anastomosis with cardiac surgery simulation. J Thorac Cardiovasc Surg. 2008;136:1486-91.

5. Fann JI, Calhoon JH, Carpenter AJ, Merrill WH, Brown JW, Poston RS, et al. Simulation in coronary artery anastomosis early in cardiothoracic surgical residency training: the Boot Camp experience. J Thorac Cardiovasc Surg. 2010;139: 1275-81.

6. Carpenter AJ, Yang SC, Uhlig PN, Colson YL. Envisioning simulation in the future of thoracic surgical education. J Thorac Cardiovasc Surg. 2008;135:477-84.

7. Joyce DL, Dhillon TS, Caffarelli AD, Joyce DD, Tsirigotis DN, Burdon TA, et al. Simulation and skills training in mitral valve surgery. J Thorac Cardiovasc Surg. 2011;141:107-12.

8. Ericsson KA, Krampe RT, Teschromer C. The role of deliberate practice in the acquisition of expert performance. Psychol Rev. 1993;100:363-406.

9. Grober ED, Hamstra SJ, Wanzel KR, Reznick RK, Matsumoto ED, Sidhu RS, et al. The educational impact of bench model fidelity on the acquisition of technical skill: the use of clinically relevant outcome measures. Ann Surg. 2004;240 374-81.

10. Anastakis DJ, Regehr G, Reznick RK, Cusimano M, Murnaghan J, Brown M, et al. Assessment of technical skills transfer from the bench training model to the human model. Am J Surg. 1999;177:167-70. 

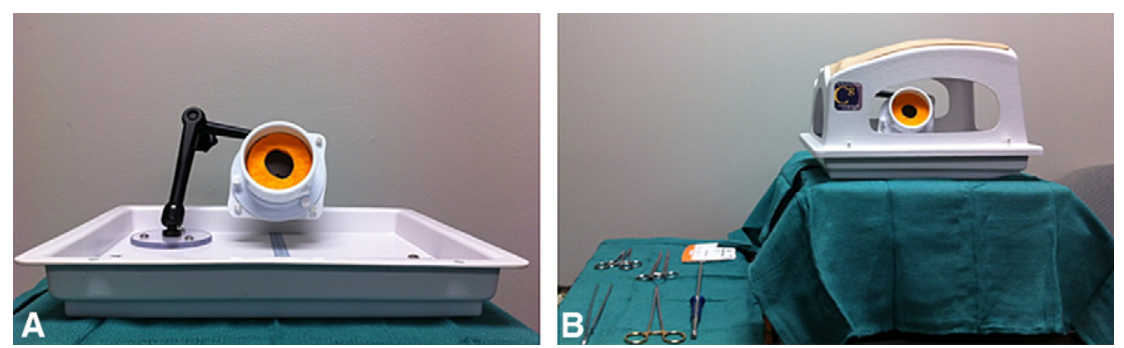

FIGURE E1. Construction of simulated mitral valve replacement training station. A, The chest wall has been removed from the simulated mitral valve replacement training station to demonstrate positioning of the "mitral insert" on mounting arm, with ruler-tapes providing a coordinate system. B, Setup of simulated mitral valve replacement training station.
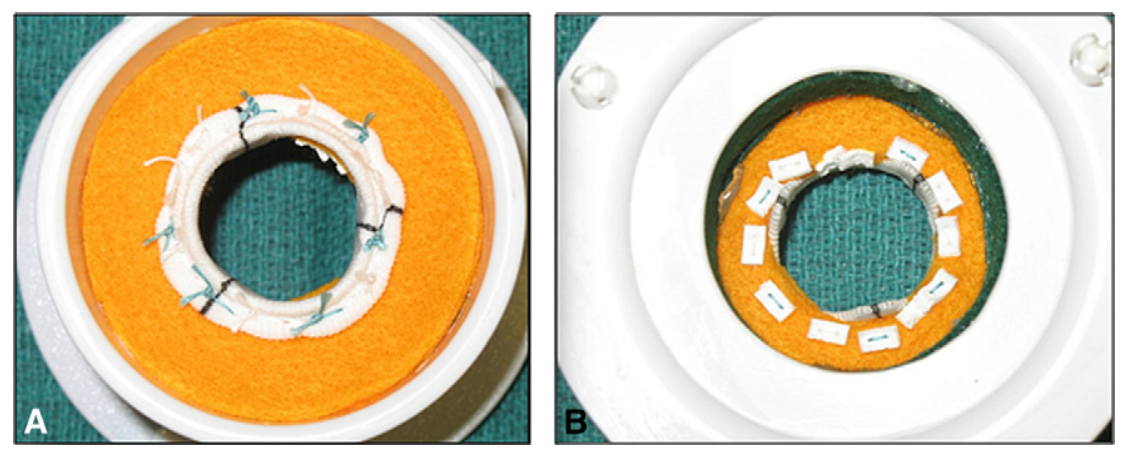

FIGURE E2. Sample "mitral insert" after completion of the simulated mitral valve replacement exercise. A, Anterior view. B, Posterior view. 